\title{
OS MARCADORES DO DISCURSO NOS CAUSOS E PANFLETOS EDITADOS DE EULÁLIO MOTTA
}

\author{
Luciane Santos Soares ${ }^{1}$; Iranildes Almeida de Oliveira Lima ${ }^{2}$ \\ 1. Bolsista PIBIC/CNPq, Graduanda em Licenciatura em Letras com Espanhol, Universidade Estadual de Feira de \\ Santana, e-mail: lu.soares1919@gmail.com \\ 2. Orientador, Departamento de Letras e Artes, Universidade Estadual de Feira de Santana, e-mail: \\ iranlima@hotmail.com
}

PALAVRAS-CHAVE: Causos; Panfletos; Marcadores do Discurso.

\section{INTRODUÇÃO}

Trata-se de um estudo dos marcadores do discurso em causos e panfletos editados de Eulálio Motta. Para este trabalho, serão analisados 10 causos e 10 panfletos de Eulálio, e, este corpus faz parte do Projeto de Pesquisa: Edições das obras inéditas de Eulálio Motta, do Núcleo de estudos Interdisciplinares em Humanidades Digitais - NEIHD, da Universidade Estadual de Feira de Santana - UEFS. O interesse por este estudo surgiu a partir da participação como bolsista de Iniciação Científica PROBIC UEFS, em que foi necessário fazer uma pesquisa sobre os marcadores do discurso utilizados por Eulálio Motta em seus causos e panfletos.

\section{MATERIAL E MÉTODOS OU METODOLOGIA (ou equivalente)}

O corpus utilizado para análise está constituído pelos causos e panfletos editados de Eulálio Motta. Ao total ele escreveu 50 causos e 57 panfletos, mas, para este trabalho, fez-se um recorte de 10 causos e 10 panfletos. Os causos foram editados e publicados no livro Bahia humorística: causos sertanejos de Eulálio Motta, de Liliane Lemos Santana Barreiros e os panfletos foram editados e publicados na obra "O Pasquineiro da roça", de Patrício Nunes Barreiros.

A análise está composta de três etapas: a primeira consiste na busca, catalogação dos marcadores do discurso nos textos de Eulálio Motta; a segunda, na análise e confrontação dos resultados; e, a terceira, na classificação dos marcadores do discurso, seguindo a proposta de Martín Zorraquino e Portolés (1999) e na seleção das informações sobre os marcadores do discurso encontrados para fazer a anotação dos marcadores do discurso nos textos de Eulálio Motta em um momento posterior.

$\mathrm{Na}$ a primeira etapa serão digitados os textos editados que ainda não se encontram disponíveis em HTML; posteriormente, serão realizados estudos sobre o conceito de marcadores do discurso para determinar os critérios que serão adotados para determinar se uma unidade linguística é marcador ou não; em seguida, aplicando os critérios elaborados, serão feitas a busca e a marcação dos marcadores encontrados nos textos em HTML;

$\mathrm{Na}$ segunda etapa, serão analisados os marcadores do discurso quanto ao seu funcionamento e a partir dos resultados obtidos serão confrontados tais resultados com os estudos que já existem sobre os marcadores; 
Na terceira etapa, seguindo a proposta de classificação de Martín Zorraquino e Portolés (1999), serão analisados e classificados os marcadores do discurso encontrados nos textos e, feita a seleção e construção das informações que farão parte das anotações.

\section{RESULTADOS E/OU DISCUSSÃO (ou Análise e discussão dos resultados)}

Como já mencionado, foram analisados 10 causos e 10 panfletos editados de Eulálio Motta.

Para esta análise foram estabelecidos alguns critérios para nortear a busca e possível observação do funcionamento dos marcadores do discurso nos causos e panfletos, como mostra a tabela 1 a seguir. Os critérios foram estabelecidos a partir do conceito de marcador do discurso de Martín Zorraquino e Portolés (1999), os quais afirmam que:

Los 'marcadores del discurso' son unidades lingüísticas invariables, no ejercen una función sintáctica en el marco de la predicación oracional -son, pues, elementos marginales- y poseen un cometido coincidente en el discurso: el de guiar, de acuerdo con sus distintas propiedades morfosintácticas, semánticas y pragmáticas, las inferencias que se realizan en la comunicación. (MARTÍN ZORRAQUINO Y PORTOLÉS, 1999, p. 4057)

Sendo assim, partindo da definição de marcador do discurso desses autores, foram estabelecidos os seguintes critérios para a busca nos textos de Eulálio Motta:

Tabela 1. Critérios para busca dos marcadores do discurso nos causos e panfletos editados de Eulálio Motta

\section{Critérios}

Unidades linguísticas invariáveis

Não exercem função sintática na predicação oracional

Elementos marginais

Guiam de acordo com suas propriedades morfossintáticas, semânticas e pragmáticas as inferências na comunicação

Também foi utilizado algumas ferramentas do WordSmith Tools 7.0, como por exemplo, a ferramenta WordList para gerar as listas de palavras com os causos e panfletos editados de Eulálio Motta para uma melhor observação dos candidatos a marcadores do discurso e posteriormente a seleção dos que seriam considerados como marcadores dentro dos critérios estabelecidos. Como mostra a figura 1 a seguir, é possível observar uma parte da lista de palavras com os 10 causos selecionados, a qual mostra a frequência de cada palavra. 


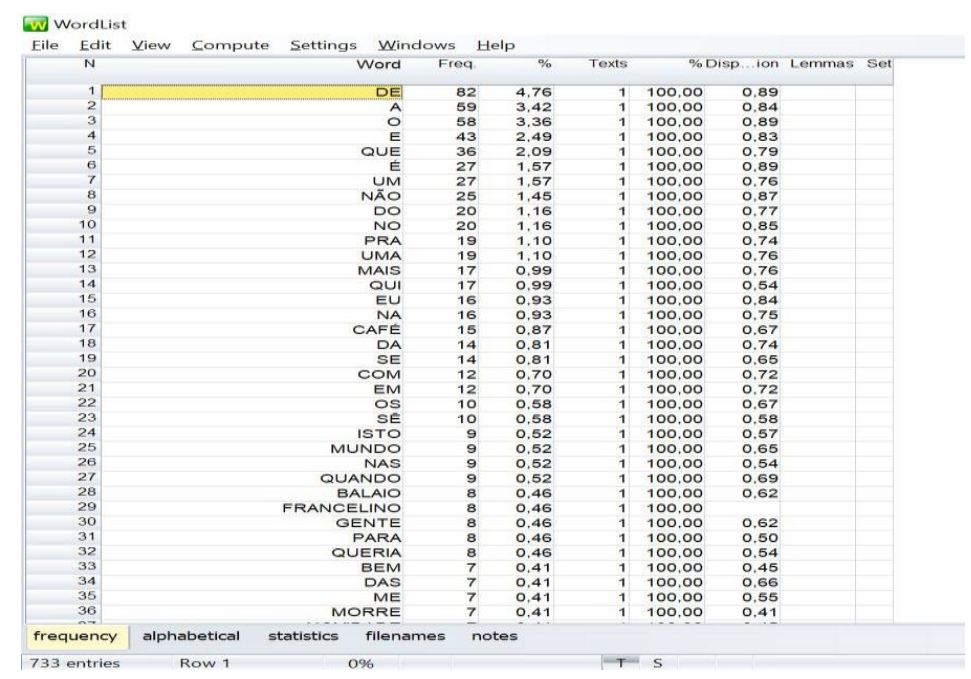

Figura 1: Lista de palavras em ordem de frequência dos 10 causos editados selecionados de Eulálio Motta.

Como é possível observar na figura 1, a lista de palavras dos causos possui um total de 733 palavras, sendo possível verificar a frequência em número e em porcentagem de cada palavra presente nos causos de Eulálio Motta.

A WordList também permite gerar a lista de palavras em ordem alfabética, como mostra a seguir a figura 2 .

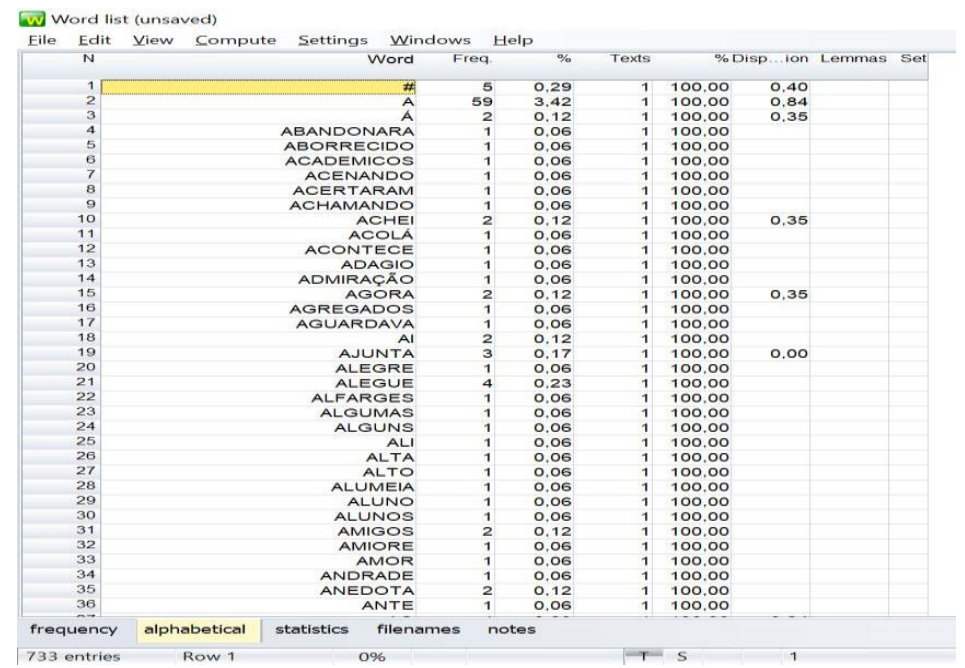

Figura 2: Lista de palavras em ordem alfabética dos 10 causos editados selecionados de Eulálio Motta.

$\mathrm{Na}$ análise, foi possível observar que os causos sertanejos editados de Eulálio Motta apresentam uma quantidade mínima de marcadores do discurso. Apesar de muitos causos retratarem a linguagem coloquial do povo de Mundo Novo, não foram encontrados muitos marcadores da modalidade conversacionais, segundo a classificação de Martín Zorraquino e Portolés (1999), o que foi um dado surpreendente já que em alguns causos aparecem diálogos. 
Já nos panfletos editados de Eulálio Motta pode-se encontrar uma quantidade maior de marcadores do discurso. E, assim como os causos sertanejos, possuem alguns diálogos, mas, a maioria dos marcadores do discurso encontrados são de outras classes que não são conversacionais, mas do tipo como, por exemplo, conectores, operadores argumentativos...

\section{CONSIDERAÇÕES FINAIS (ou Conclusão)}

Os marcadores do discurso são unidades linguísticas que podem contribuir de forma significativa para a construção de textos escritos e orais.

$\mathrm{Na}$ escrita de seus causos e panfletos, Eulálio Motta fez uso de uma grande quantidade de elementos coesivos, porém, no que diz respeito aos marcadores do discurso, essa quantidade reduz um pouco. Nos causos sertanejos é onde menos aparecem marcadores do discurso.

De modo geral, pode-se dizer que a pesquisa acerca dos marcadores discursivos nos causos e panfletos editados de Eulálio Motta permitiu conhecer um pouco sobre a sua escrita e quais elementos ele utilizou para estruturar seus textos. E, observar a presença ou ausência de marcador do discurso em tais obras são dados que contribuem para a continuação de possíveis estudos dessas unidades em outras obras de Eulálio Motta como também de outros autores.

\section{REFERÊNCIAS}

BARREIROS, Patrício Nunes. O Pasquineiro da Roça, a hiperedição dos panfletos de Eulálio Motta. Feira de Santana: UEFS Editora, 2015.

BARREIROS, Liliane lemos Souza. Bahia Humorística: causos sertanejos de Eulálio Motta. Feira de Santana: UEFS Editora, 2016.

CABEZUDO, Marco A. Sobrevilla, et all Anotação de Sentidos de Verbos no Córpus CSTNews. Disponível em: <http://conteudo.icmc.usp.br/pessoas/taspardo/NILC-TR-1405.pdf>. Acesso em 26 mar. 2017.

MARCUSCHI, L. A. Análise da Conversação. São Paulo, Ática, 1986.

MARTÍN ZORRAQUINO, Ma; PORTOLÉS LÁZARO, J. Los marcadores del discurso. En: BOSQUE, I.; DEMONTE, V. Eds., Gramática descriptiva de la lengua española, Vol. III. Madrid, Espasa, cap. 63, p. 4051-4213, 1999.

TOSCANO MARTELOTTA, M. E. Gramaticalização de então. En: M. E. Toscano Martelotta et al. Gramaticalização no portugués do Brasil - uma abordagem funcional. Rio de Janeiro, Tempo Brasileiro, 1996.

URBANO, H. Marcadores conversacionais: aspectos conceituais. En: Anais do VII encontro da ANPOLL, p. 812-822, 1993. 